\title{
Dominance in monkeys: Effects of social change on performance and biochemistry ${ }^{1,2}$
}

\author{
W. F. ANGERMEIER AND J. B. PHELPS, PRIMATE NEURO- \\ SCIENCES LABORATORY, FLORIDA PRESBYTERIAN \\ COLLEGE, St. Petersburg, Fla. 33733, H. H. REYNOLDS, $A R L$. \\ HOLLOMAN AFB, New Mexico, AND R. DAVIS, VA RE- \\ SEARCH CENTER, Bay Pines, Florida
}

Twenty-four differentially reared male rhesus monkeys were used in this experiment. The animals were tested on a four choice match-io-sample task. The results indicated that (1) performance of complex discrimination improves for social subdominant animals changed to isolation; (2) performance of the same task shows a decrement for isolated animals which became subdominant after a change to a state of social companionship; (3) control animals and dominant animals were not affected by social changes; and (4) social status along the dominant-subdominant scale seems to be more important for prediction of performance than the perceptual conditions of the living environment

Many experiments have been published which describe the effect of early experience upon adult performance. From the wealth of data, selected studies in which perceptual enrichment, group rearing and social isolation were important variables, are discussed here.

Animals reared in perceptually enriched environments performed significantly better than their isolated counterparts on a closed-field test, as shown by Hymovitch (1952). Such animals also performed better on reversal discrimination under food deprivation (Krech, Rosenzweig, \& Bennett, 1962), and showed more advantageous brain chemistry and anatomy (Krech, Rosenweig, \& Bennett, 1966). Socially facilitated reduction of the fear response in animals raised in groups was observed by Morrison \& Hill (1967) and Angermeier, Philhour, \& Higgins (1965). Group rearing increases the effectiveness of social reinforcement (Angermeier, 1960) and the likelihood of choice of social partner reared under like conditions (Pratt \& Sackett, 1967). Isolation takes its toll not only in terms of implicit pathological conditions, as shown by Kaufman \& Rosenblum (1967), but also in endocrinopathy (Hatch, Wiberg, Balazs, \& Grice, 1963).

Although some of the effects of early restriction are undoubtedly irreversible or extremely difficult to modify (Harlow, 1962), there is evidence that this is not uniformly the case. Rosenweig (1966), i.e., pointed out that "the cortex of the adult rat brain is as capable of adaptive growth as is the cortex of the young animals." Baron, Kish, \& Antonitis (1962) found that the effects of early isolation or social contact in chickens may be modified by later social experiences. Reynolds (1963) showed that a change to a social environment could be interpreted to be "therapeutic" for animals previously reared in isolation. The hypothesis implicit in Reynolds' findings was tested in this study in a group of male rhesus monkeys.

Subjects. Twenty-four male rhesus monkeys, approximately $20-22$ months of age at the beginning of the main testing phase, were used as Ss. Six animals each had previously been reared under one of four conditions: (1) Strict Isolation (SI)-one animal per cage, no visual or tactual contact with peers; (2) Partial Isolation (PI)-one animal per cage, with visual but limited tactual contact between peers; (3) Social Environment (S)-two animals per cage, some interaction between cages; and (4) Enriched Social Environment (ES)-two animals per cage, with play objects, swings, colored rotating lights and a daily 8-h television-watching schedule. All animals were maintained on a diet of fresh fruit, biscuits and ad/lib water.

Apparatus. The apparatus consisted of a performance cage 18 in. wide, 24 in. long, and 32 in. high. All sides of the apparatus except the tip and the performance panel were made of 3/8 in. stainless steel rods, spaced 1 in. center to center. The top of the cage was constructed of $1 / 2$ in. clear plastic. One of the sides, $18 \mathrm{in}$. wide and $32 \mathrm{in}$. high, constituted the performance panel. Centered on it were five piastic pushbuttons, arranged in the shape of a summetrical cross. The pushbutton in the center served as a master sample (MS) and could not be depressed. The other four pushbuttons (PBs) were resting on microswitches, which could be activated by a horizontal depression of $1 / 16$ in. Affixed to the back of all pushbuttons (MS and PBs) were inline digital display units (IDDs) which permitted the presentation of various geometric symbols and colors. In this experiment, only four symbols were used: $O, \square, \Delta$, and + . The experimental contingencies were programmed as follows: A 1000 cps tone was given; 2 sec later shock ( $1-4 \mathrm{~mA}$ ) activated the rods of the performance cage; $1 \mathrm{sec}$ after the onset of shock, the MS and the PBs presented the symbols to the animal. A depression of the PB which matched the MS turned off the shock and gave the animal a 15 -sec period of time-out (TO). The animals were given 50 trials per session. Since the stepper contained 26 steps in sequence, the animals never started their trial sequence at the same point from one day to the next.

Procedure. All experimental Ss were exposed to the 50-trial session on alternate days, weekends and holidays included. When $80 \%$ of the animals reached an asymptotic level of performance (less than 5\% deviation over 250 trials), the main experimental phases were begun. Two of the four animals in each rearing condition were exposed to altered social conditions: The ES animals were changed to $S I$ environment and vice versa, and the $S$ animals were placed into the PI environment and vice versa. Two more animals remained in their respective rearing conditions but were exposed to behavioral testing. Two more animals also remained in their original social conditions, but were not exposed to the behavioral testing procedures. This group was used primarily as a control group for the biochemical assessments. Data gathered from this experiment consisted of number of first correct responses on the match-to-sample task and blood samples. The behavioral data were gathered for a 10-day period preceding the changed social environment phase, the 30-day changed social environment phase, and a 10-day period after the changed social environment phase. Blood samples were gathered once each during the pre- and post-changed social environment phase and three times at regular intervals during the changed social environment phase. The blood samples were analyzed for Cholinesterase, Calcium, Tyrosine, Cholesterol, Senum Total Protein, and Serum Glutamic Oxalacetic Transaminase. The selection of these particular assessments was dictated by the findings of a previous study in which these measures were found to be particularly sensitive to stress in a series of 21 analyses performed on rhesus monkeys (Angermeier, Phelps, \& Reynolds, 1967). None of the animals were handled except during blood withdrawal.

Results. Per cent first correct responses were analyzed by a Type III analysis of variance design, suggested by Lindquist

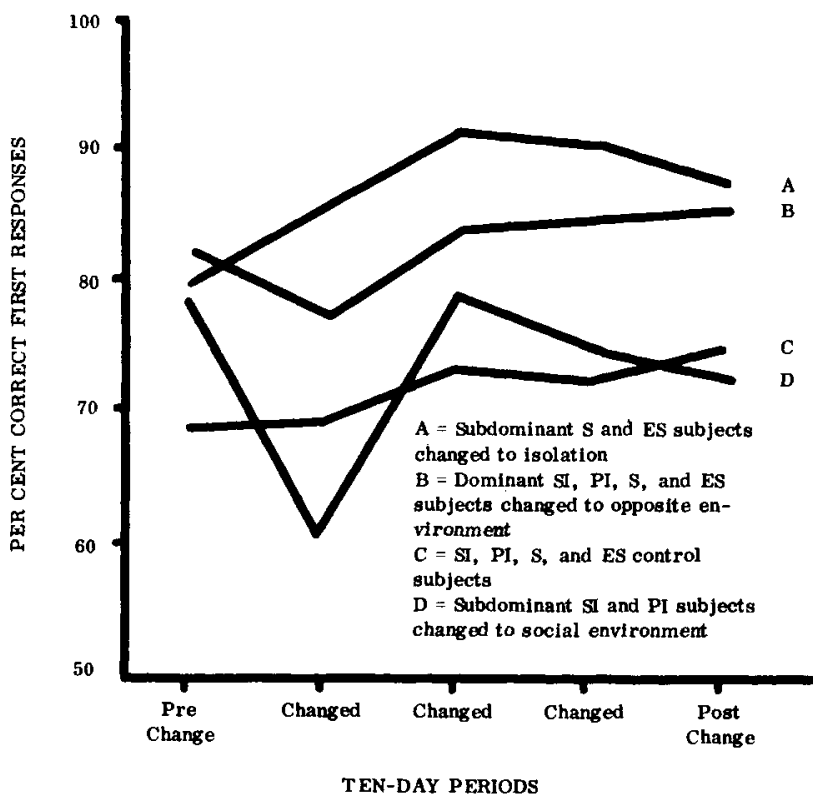

Fig. 1. The effects of changed social environments upon per cent first correct responses of a match-to-sample task. 
Table 1

Changed Environments and Optimal Improvement in Biochemistry

\begin{tabular}{lcc}
\multicolumn{1}{c}{ Measure } & Improvement & p \\
\hline Cholinesterase & Yes & .01 \\
Calcium & Yes & .01 \\
Tyrosine & Yes & $\mathrm{N} / \mathrm{S}$ \\
Cholesterol & No & $\mathrm{N} / \mathrm{S}$ \\
Serum Total Protein & Yes & .01 \\
SGOT & Yes & $\mathrm{N} / \mathrm{S}$ \\
\hline
\end{tabular}

(1953). Only temporal sequence proved to be significant $(\mathrm{F}=$ 3.49 , df $=4 / 32, p<.05)$. A separation of the animals' performance along the dominance-subdominance dichotomy can be seen in Fig. 1. Here, the change in performance of the dominant animals and the control animals shows little or no increment or decrement. The formerly subdominant animals now changed to isolation actually showed an increment in performance efficiency. The formerly isolated animals which became subdominant in the social situation showed a decrement in performance. In order to determine the significance of these changes, the maximum decrements and increments in per cent first correct responses for each group between the pre-change period and the respective change period was computed by using $t$ tests for differences between correlated means. These computations showed that there was a significant increment in performance under Condition $\mathrm{A}$ in Fig. 1, and a significant decrement under Condition $D$ in Fig. 1. For Condition $A, t=2.62$, $\mathrm{df}=10, \mathrm{p}<.05$; and for Condition $\mathrm{D}, \mathrm{t}=4.58, \mathrm{df}=10, \mathrm{p}<.01$

The raw data of the biochemical assessments were also analyzed by a Type III analysis of variance. The results of this analysis showed that Cholinesterase and Clacium discriminated between the experimental and the control groups (with the control group showing the more advantageous values). Again appropriate t tests were performed to assess the possible improvement between pre-change period and change period in biochemical values of animals placed in altered social environments. The data of that analysis can be seen in Table 1. From this Table it is evident that virtually all biochemical measures showed improvement, with those of Cholinesterase, Calcium, and Serum Total Protein being statistically significant.

Discussion. The obvious finding of this experiment seems to be the observation that change of environment per se has probably very little or no effect upon behavior. The important factor is the social position which is attained in the new environment or the social position which is being left behind in the old environment. For animals subject to harrassment by a strongly dominant partner, a change to isolation improves both performance and biochemistry. Interesting to note is the observation that all of these changes seem to be more or less temporary. Rapid adaptation to the new environmental conditions are the rule. Compared with the data from Reynolds' (1963) study, monkeys show the behavior which one would expect with increasing complexity of social organization at the primate level: social relationships are more important than attending perceptual framework.

\section{REFERENCES}

ANGERMEIER, W. F. Some basic aspects of social reinforcements in albino rats. J. comp. physiol. Psychol, 1960, 53, 364-367.

ANGERMEIER, W. F., PHELPS, J. B., \& REYNOLDS, H. H. The relationship between performance under stress and blood biochemistry in monkeys. Psychon. Sci., 1967, 8, 389-390.

ANGERMEIER, W. F., PHILHOUR, P., \& HIGGINS, J. Early experience and social grouping in fear extinction of rats. Psychol. Rep., 1965, 16, 1005-1010.

BARON, A., KISH, G. B., \& ANTONITIS, J. J. Effects of early and late isolation on aggregative behavior in the domestic chicken. J. genet. Psychol., 1962, 100, 355-360.

HARLOW, H. F. The heterosexual affectional system in monkeys. Amer. Psychologist, 1962, 17, 1-9.

HATCH, A., WIBERG, G. S., BALAZS, T., \& GRICE, H. C. Long-term isolation stress in rats. Science, 1963, 142, 507.

HYMOVITCH, B. The effects of experimental variations on problem solving in the rat. J. comp. physiol. Psychol., 1952, 45, 313-321.

KAUFMAN, L. C., \& ROSENBLUM, L. A. Depression in infant monkeys separated from their mothers. Science, 1967, 155, 1030-1031.

KRECH, D., ROSENZWEIG, M. R., \& BENNETT, E. I. Environmental impoverishment, social isolation and changes in brain chemistry and anatomy. Physiol. \& Behav., 1966, 1, 99-104.

KRECH, D., ROSENZWEIG, M. R., \& BENNETT, E. I. Relations between brain chemistry and problem-solving among rats raised in enriched and improverished environments. J. comp. physiol. Psychol., 1962, 55, $801-807$.

LINDQUIST, E. F. T. Design and analysis of experiments. Boston: Houghton-Mifflin Co., 1953.

MORRISON, B. J., \& HILL, W. F. Socially facilitated reduction of the fear response in rats raised in groups or isolation. J. comp. physiol. Psychol, $1967,63,71-76$.

PRATT, C. L., \& SACKETT, G. P. Selection of social partners as a function of peer contact during rearing. Science, 1967, 155, 1133-1135.

REYNOLDS, H. H. Effects of rearing and habitation in social isolation on performance of an escape task. J. comp. physiol. Psychol., 1963, 56, 520-525.

ROSENZWEIG, M. R. Environmental complexity, cerebral change, and behavior. Amer. Psychologist, 1966, 21, 321-332.

\section{NOTES}

1. This report was sponsored by AF Contract AF29600-67-C-0011 between the Aeromedical Research Laboratory, Holloman AFB, New Mexico and Florida Presbyterian College.

2. A more detailed report is available upon request. 